\title{
Study of the Effect of Micro patterning on Apatite Formation in Osteoblasts
}

\section{Yizhi Meng*}

Department of Materials Science \& Engineering, Stony Brook University, New York, USA

Collaborators at Stony Brook University (Stony Brook, New York, USA) and New York Institute of Technology (Old Westbury, New York, USA) recently conducted a research project to investigate bone mineralization on artificially patterned biomaterials. This project aimed to seek out novel ways to enhance the osteogenic capability of osteoblasts by culturing them on substrates containing various micro topographies. This was the first study that combines micro patterning and synchrotron techniques to examine in-situ apatite production of cultured cells in response to altered surface dimension.

The rising demand for artificial orthopedic replacements is anticipated over the course of the next decade, as already there has been a steady increase in hip fractures [1] and artificial knee and hip replacements [2]. Present day knee and hip implants, however, only last an average of 15 years due to implant rejection by the body and mechanical failure due to a more physically active population [3]. With a rapid surge in the elderly population, the demand for better strategies in regenerative medicine is also expected to increase.

A recent project conducted at Stony Brook University investigated the potential of micro fabricated materials as a novel orthopedic implant material. This project utilized a micro patterning approach to examine the osteogenic response of cultured osteoblasts on patterned silicon. To evaluate their results, the research team combined traditional cell culture with synchrotron characterization tools.

The investigators used:

- Two murine osteoblast-like cell lines: MC3T3-E1 sub clones 4 and 24.

- One biomaterial: $<100>$ orientation silicon.

- Two micro patterns fabricated using photolithography and reactive ion etching: $2 \mu \mathrm{m}(2 \mu \mathrm{m}$ depth, $10 \mu \mathrm{m}$ pitch $)$ and $20 \mu \mathrm{m}(2 \mu \mathrm{m}$ depth, $30 \mu \mathrm{m}$ pitch).

- One synchrotron X-ray diffraction beam line (X6B) located at the Department of Energy (DOE)-funded National Synchrotron Light Source at Brookhaven National Laboratory (Upton, New York, USA).

One particularly novel aspect of this study is that no a priori bioceramic coating (i.e. hydroxyapatite) was used, in contrast to previous reports in the literature (Figure 1).

Results from this study revealed that not only was the micro patterned silicon able to support osteoblast mineralization, the surface dimension also played a role in the osteogenic potential of the cells.

The lead author of the study, Dr. Kathryn Dorst, explains that "the dimensions of surface features modify the way cells interact with a material and greatly affect its cytocompatibility. These characteristics elicit variations in downstream responses through minute changes in cytoskeletal tension that ultimately guide cell fate".

Collaborator Dr. Michael Hadjiargyrou (Professor and Chair, Department of Life Sciences, New York Institute of Technology, Westbury, New York, USA) adds that "as the world's aging population increases, it will become even more pertinent for us to be able to design orthopedic implants that result in long term successful osteo integration and resist the common occurrence of loosening".

\section{References}

1. Johnell O, Kanis JA (2006) An estimate of the worldwide prevalence and disability associated with osteoporotic fractures. Osteoporos Int 17: 17261733.

2. Freid VM, Bernstein AB (2010) US. National Center for Health, Health care utilization among adults aged 55-64 years : how has it changed over the past 10 years?Hyattsville, MD U.S. Dept. of Health and Human Services, Centers for Disease Control and Prevention, National Center for Health Statistics.

3. Bozic KJ, Rubash HE, Berry J, Durbhakula SM (2010) Hip and Knee Replacement.

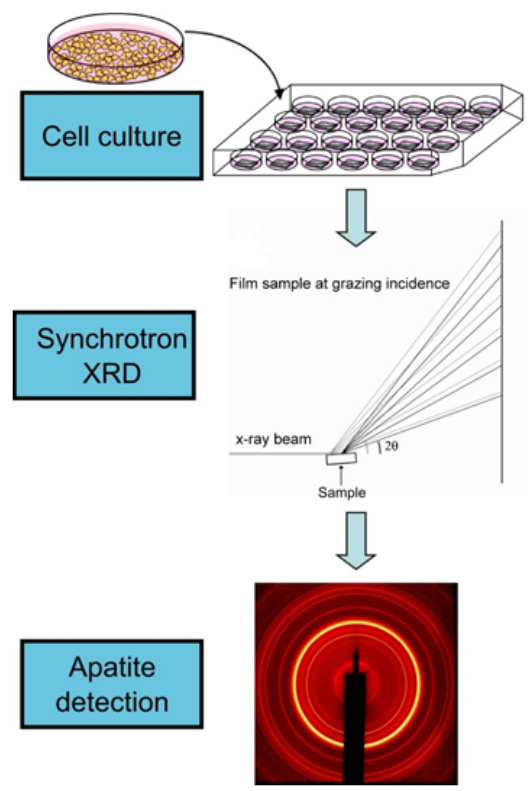

Figure 1: Overview of in-situ synchrotron XRD analysis of apatite formation in cultured osteoblasts.

*Corresponding author: Yizhi Meng, Materials Science and Engineering Stony Brook University, Stony Brook, NY, USA, Tel: +1 631632 8552; E-mail: yizhi.meng@stonybrook.edu

Received January 09, 2014; Accepted January 15, 2014; Published January 22 2014

Citation: Meng Y (2013) Study of the Effect of Micro patterning on Apatite Formation in Osteoblasts. Bioceram Dev Appl 4: e102. doi: 10.4172/2090-5025.1000e102

Copyright: @ 2013 Meng Y. This is an open-access article distributed under the terms of the Creative Commons Attribution License, which permits unrestricted use, distribution, and reproduction in any medium, provided the original author and source are credited. 


\section{How to read this compendium}

This Compendium to the Manual for the EU Project GAMBA is meant to give you a deeper insight into the topics around the project. You will find more information about the symptoms and the treatment of osteoarthritis as well as contact points and selfhelp groups. There is background information about the basic components of life, stem cells, gene therapy and nanomedicine. What is what exactly, which innovations are already in use, and what is the current state of research? You will also find information on legal and ethical aspects of the GAMBA topics that are worth considering.

Last but not least the extensive Glossary with its $\rightarrow$ cross-references will be a valuable source of information.

This compendium was originally written for citizen and patient panels in Germany, which took place in May 2011 and January 2012. Therefore the numbers and statistics often refer to Germany, Irish numbers were added on a case by case basis, if available.

\section{Imprint}

Publisher: ScienceDialogue Dr. K. Zöller, M. Schüpphaus, S. Siebert GbR Zöpfstr. 25, 82362 Weilheim, www.sciencedialogue.de

Text: $\quad$ Beatrice Lugger; Ethics Chapter: K. Zöller

Translation: Christine Ritter, Galway, Ireland Originally published in Germany as "Ein Begleitbuch zum Handbuch Grundlagen, Wissenswertes, Historie"

Editors: $\quad$ K. Zöller, M. Schüpphaus, S. Siebert

Layout: S. Siebert

Print : $\quad$ Clondalkin Group, Dublin

(C) 2012 all rights reserved by ScienceDialogue GbR; bibliography: see last page 